\title{
Designs of 10 MW Air-core and Iron-core HTS Wind Power Generators
}

\author{
Hae-Jin Sung*, Minwon Park* and In-Keun Yu ${ }^{\dagger}$
}

\begin{abstract}
High Temperature Superconducting (HTS) synchronous generators can be designed with either an air-core type or iron-core type. The air-core type has higher efficiency under rated rotating speed and load than the iron-core type because of the iron losses which may produce much heat. However, the total length of HTS wire in the air-core type is longer than the iron-core type because the generated magnetic flux density of the air-core type is low. This paper deals with designs of $10 \mathrm{MW}$ air-core and iron-core HTS wind power generators for wind turbines. Fully air-core, partially iron-core, and fully iron-core HTS generators are designed, and various stator winding methods in the three HTS generators are also considered, such as short-pitch concentrated winding, full-pitch concentrated winding, short-pitch distributed winding, and full-pitch distributed winding. These HTS generators are analyzed using a 3D finite elements method program. The analysis results of the HTS generators are discussed in detail, and the results will be effectively utilized for large-scale wind power generation systems.
\end{abstract}

Keywords: Direct-driven, Offshore wind power, Superconducting generator, Superconducting wire, Wind power generation

\section{Introduction}

Offshore wind power capacity contributed $470 \mathrm{MW}$ to worldwide installations of wind power in 2011. The total installed capacity of offshore wind power from January of 2012 to October of 2012 was 1,314 MW. Offshore wind farms are currently under construction in Belgium, Denmark, Germany, the UK, China, Korea, and Japan with a total expected capacity upon completion of nearly 100 GW. The average annual growth rate for new installations is expected to be $81.8 \%$ until 2016 [1].

A direct-drive type high temperature superconducting (HTS) synchronous generator has a smaller physical size and a higher power density per volume ratio than conventional generators. Because of these advantages, HTS generators are becoming an interesting solution to the need for large scale wind turbines [2-4]. The HTS generators can be designed with either an air-core type or iron-core type. The air-core type has higher efficiency under rated rotating speed and load than the iron-core type because of the iron losses that can produce a significant amount of heat. However, the total length of the HTS wire in the air-core type is longer than the iron-core type because the generated magnetic flux density of the air-core type is low [5-7].

The main objective of this paper is to design $10 \mathrm{MW}$ aircore and iron-core HTS wind power generators which are

$\dagger$ Corresponding Author: Dept. of Electrical Engineering, Changwon

National University, Korea (yuik@changwon.ac.kr).

* Dept. of Electrical Engineering, Changwon National University,

Korea (haejin90@changwon.ac.kr).

Received: February 11, 2014; Accepted: September 29, 2014 the fully air-core, partially iron-core and fully iron-core generators to find an optimal design for large-scale wind power generation systems. The various stator winding methods of the HTS generators are also considered for more details of the optimal design, such as short-pitch concentrated winding (SCW), full-pitch concentrated winding (FCW), short-pitch distributed winding (SDW), and full-pitch distributed winding (FDW). The magnetic field distribution of the HTS generators is analyzed using a 3D finite elements method (FEM) program.

The most efficient design, the fully iron-core HTS generator with FDW, is recommended considering all items such as torque ripple, efficiency, volume, weight, and total length of HTS wire. The analyzed results will be effectively utilized for large-scale wind power generation systems.

\section{Basic Design of the 10 MW HTS Generators}

\subsection{HTS wire and iron-core properties}

The thickness, width, and minimum bend diameter of the HTS wire are $0.1 \mathrm{~mm}, 4 \mathrm{~mm}$, and $11 \mathrm{~mm}$, respectively. The detailed specifications of the engineering critical current density versus the perpendicular magnetic field of the HTS wire at the operating temperature are referred from SuperPower Inc. [8]. The iron cores in the three types of generators are exposed to a high magnetic field. The material of iron cores such as in the magnetic shield, rotor body, or stator body is M-27. 


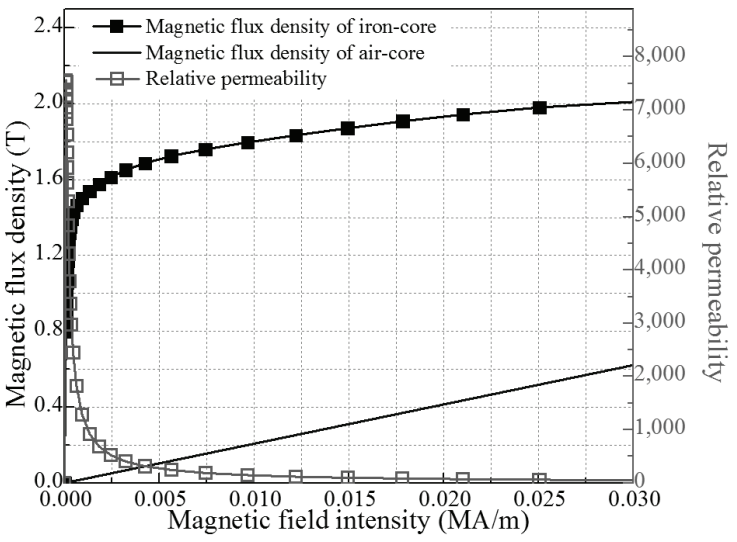

(a) B-H curves of a relatively low magnetic field

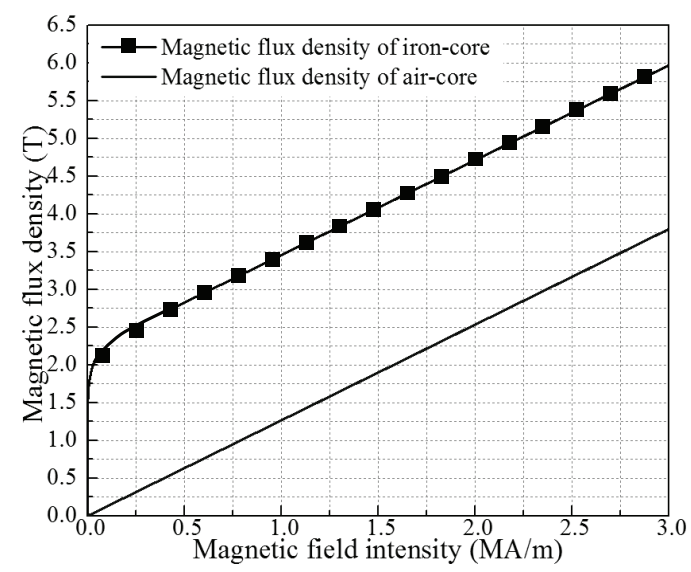

(b) B-H curves with a high magnetic field

Fig. 1. The magnetic curves of the iron-core and air-core

Iron manufacturers generally provide the magnetic properties under $2 \mathrm{~T}$. In the range of the significantly high magnetic field over the saturation magnetic field of ironcore, the magnetic properties of iron-core should be defined $[9,10]$.

Fig. 1 shows the nonlinear magnetization curve $(\mathrm{B}-\mathrm{H}$ curve) and relative permeability of $\mathrm{M}-27$ and the linear magnetization curve of air-core.

\subsection{Three types of the HTS generators}

The three types of HTS generators consist of an HTS rotor coil, rotor body, vacuum vessel, stator copper coil, and stator body. Among the three types, the fully air-core type, which contains a rotor body and a stator body, uses nonmagnetic material such as stainless steel and fiber reinforced plastics. The magnetic shield in the fully aircore type uses magnetic material such as laminated silicon steel (M-27). The partially iron-core type with a stator body and a rotor body consists of M-27 and SUS304. In the case of the fully iron-core type, M-27 is used in the rotor body and the stator body. Fig. 2 shows the configurations of the fully air-core type HTS generator and iron-core type HTS generators. The partially iron-core type

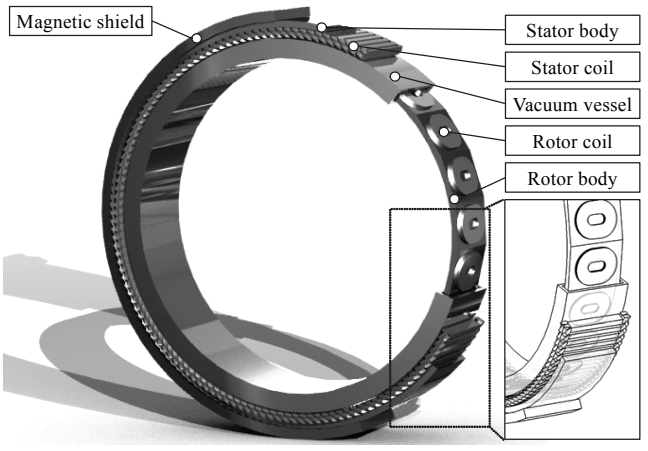

(a) Fully air-core HTS generator

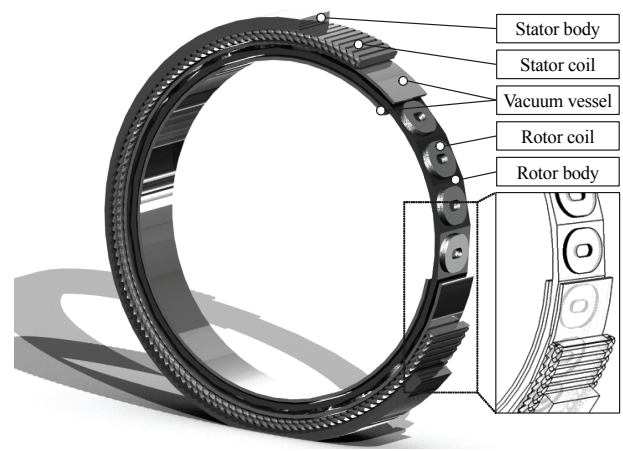

(b) Iron-core HTS generators

Fig. 2. The configurations of the HTS generators

Table 1. Basic design specifications of the $10 \mathrm{MW}$ class HTS generators

\begin{tabular}{c|c}
\hline Specifications & Value \\
\hline Rated output power & $10.5 \mathrm{MW}$ \\
\hline Rated line-to-line voltage & $6.6 \mathrm{kV}$ \\
\hline Rated armature current & $918.5 \mathrm{~A}$ \\
\hline Rated rotation speed & $10 \mathrm{rpm}$ \\
\hline Rated torque & $10 \mathrm{MNm}$ \\
\hline Operating temperature & $20 \mathrm{~K}$ \\
\hline Num. of rotor poles & 24 \\
\hline Num. of DPC layers & 5 \\
\hline
\end{tabular}

and the fully iron-core type have the same configuration.

The basic design specifications of HTS generators in wind power systems are shown in Table 1. The drive-train of the HTS generators is the direct-drive type, and the space factors of the HTS rotor coil and stator copper coil are 0.8 and 0.5 , respectively. The HTS rotor coil is a racetrack type double pancake coil (DPC), and the current density of stator copper coil considering water cooling is 6 $\mathrm{A} / \mathrm{mm}^{2}$. The air gap length and effective length of DPC are $20 \mathrm{~mm}$ and $500 \mathrm{~mm}$.

\section{Detailed Designs of the HTS Generators Considering Stator Winding Methods}

The stator winding methods are divided into a single layer and a double layer winding. The single layer winding 
has one coil side per slot, while the double layer winding has two coil sides per slot. The double layer winding can be classified as a full-pitch or a short-pitch winding.

When the two coil sides of the stator coil are 180 electrical space degrees apart, the winding is the full-pitch winding method, such as FCW or FDW. When the two coil sides of the stator coil are less than 180 electrical space degrees apart, the winding is the short-pitch winding method, such as SCW or SDW.

In the case of SCW and FCW, the number of slots is 72 due to the concentrated winding i.e. one slot per pole per phase. In HTS generators with SDW and FDW, the number of slots is 144 due to the distributed winding, with two slots per pole per phase.

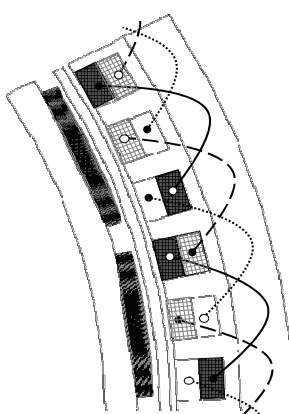

$\mathrm{SCW}$

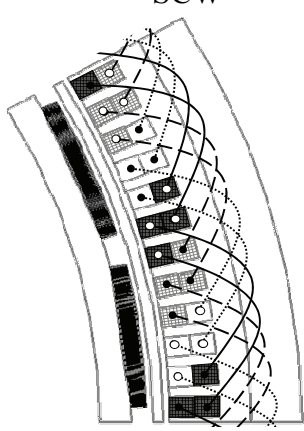

SDW
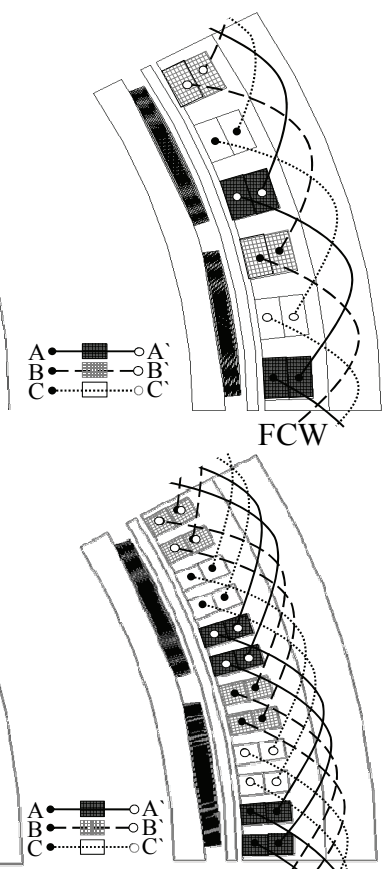

FD_W.

Fig. 3. Winding diagrams of the HTS generators

Table 2. Control parameters of the 10 MW HTS generators

\begin{tabular}{c|c|c|c|c}
\hline \multicolumn{5}{c}{ Fully air-core type } \\
\hline Stator winding & SCW & FCW & SDW & FDW \\
\hline Operating current (A) & 106 & 106 & 106 & 106 \\
\hline Turns of DPCs & 1,350 & 1,260 & 1,287 & 1,260 \\
\hline Num. of stator slots & 72 & 72 & 144 & 144 \\
\hline Turns of stator coils & 50 & 50 & 25 & 25 \\
\hline \multicolumn{5}{c}{ Partially iron-core type } \\
\hline Stator winding & SCW & FCW & SDW & FDW \\
\hline Operating current (A) & 109 & 109 & 109 & 109 \\
\hline Turns of DPCs & 1,000 & 975 & 980 & 975 \\
\hline Num. of stator slots & 72 & 72 & 144 & 144 \\
\hline Turns of stator coils & 50 & 50 & 25 & 25 \\
\hline \multicolumn{6}{|c|}{ Fully iron-core type } \\
\hline Operating current (A) & SCW & FCW & SDW & FDW \\
\hline Turns of DPCs & 920 & 104 & 104 & 104 \\
\hline Num. of stator slots & 72 & 72 & 144 & 144 \\
\hline Turns of stator coils & 50 & 50 & 25 & 25 \\
\hline
\end{tabular}

Fig. 3 shows the winding diagrams of the HTS generators. The magnetic field effects of the generators are different from each stator winding method. Hence, the control parameters of each generator should be controlled to generate the rated line-to-line voltage. Table 2 shows the control parameters of the HTS generators. The operating currents apply a $20 \%$ safety margin of critical currents in the superconducting field coils.

\section{Simulation and Comparative Analysis}

\subsection{FEM analysis results of the HTS generators}

The 1/24 models for the 10 MW HTS generators are designed in detail and simulated using 3D FEM tool. Table 3 shows the total harmonic distortion (THD) values of the HTS generators.

The voltage THD while powering $100 \%$ resistive load of a synchronous machine must be less than 5\% [11]. Therefore, all designs are appropriate to standard IEC 60034-1 conditions.

Table 3. THD values of the three types of $10 \mathrm{MW}$ HTS generators

\begin{tabular}{c|c|c|c|c}
\hline Stator winding & SCW & FCW & SDW & FDW \\
\hline Fully air-core type (\%) & 0.51 & 0.49 & 0.45 & 0.18 \\
\hline Partially iron-core type (\%) & 3.75 & 3.05 & 1.67 & 1.87 \\
\hline Fully iron-core type (\%) & 3.20 & 3.10 & 2.00 & 3.01 \\
\hline
\end{tabular}

Table 4. Losses and efficiencies of the 10 MW HTS generators

\begin{tabular}{|c|c|c|c|c|}
\hline \multicolumn{5}{|c|}{ Fully air-core type } \\
\hline Stator winding & SCW & FCW & SDW & FDW \\
\hline Stator coil $(\mathrm{kW})$ & 154 & 154 & 154 & 154 \\
\hline Stator body $(\mathrm{kW})$ & - & - & - & - \\
\hline Vacuum vessel (kW) & 2.88 & 2.21 & 1.02 & 0.92 \\
\hline Rotor body $(\mathrm{kW})$ & - & - & - & - \\
\hline Windage loss $(\mathrm{kW})$ & 0.17 & 0.17 & 0.17 & 0.17 \\
\hline Total loss $(\mathrm{kW})$ & 157.1 & 156.4 & 155.2 & 155.1 \\
\hline Efficiency $(\%)$ & 98.50 & 98.50 & 98.50 & 98.50 \\
\hline \multicolumn{5}{|c|}{ Partially iron-core type } \\
\hline Stator winding & SCW & FCW & SDW & FDW \\
\hline Stator coil $(\mathrm{kW})$ & 154 & 154 & 154 & 154 \\
\hline Stator body $(\mathrm{kW})$ & 9.1 & 6.75 & 7.80 & 7.13 \\
\hline Vacuum vessel $(\mathrm{kW})$ & 72 & 38.4 & 21 & 20 \\
\hline Rotor body $(\mathrm{kW})$ & - & - & - & - \\
\hline Windage loss $(\mathrm{kW})$ & 0.15 & 0.14 & 0.14 & 0.14 \\
\hline Total loss $(\mathrm{kW})$ & 235 & 199 & 183 & 181 \\
\hline Efficiency (\%) & 97.76 & 98.10 & 98.26 & 98.28 \\
\hline \multicolumn{5}{|c|}{ Fully iron-core type } \\
\hline Stator winding & SCW & FCW & SDW & FDW \\
\hline Stator coil $(\mathrm{kW})$ & 154 & 154 & 154 & 154 \\
\hline Stator body $(\mathrm{kW})$ & 8.21 & 6.71 & 7.74 & 7.19 \\
\hline Vacuum vessel (kW) & 42 & 30 & 12 & 12 \\
\hline Rotor body (kW) & 0.42 & 0.42 & 0.42 & 0.42 \\
\hline Windage loss $(\mathrm{kW})$ & 0.14 & 0.14 & 0.14 & 0.14 \\
\hline Total loss $(\mathrm{kW})$ & 204.8 & 191.3 & 174.3 & 173.8 \\
\hline Efficiency $(\%)$ & 98.05 & 98.05 & 98.05 & 98.05 \\
\hline
\end{tabular}


The torque ripple is an important property to consider when designing a rotating machine. A lower torque ripple is required to minimize the vibrations and noise of the machine, and to maximize the lifetime of the machine.

The torque ripple depends on the stator winding methods, slot shapes of stator, and so on. In this paper, the torque ripples of HTS generators are only analyzed using stator winding methods. Fig. 4 shows the electromagnetic torque waveforms of three types of HTS generators. The torque ripples of the fully air-core types are lower than the partially iron-core types and fully iron-core types because the magnetic field of the stator parts in fully air-core types is uniformly distributed. Of the iron-core types, the partially iron-core type with SDW and the fully iron-core

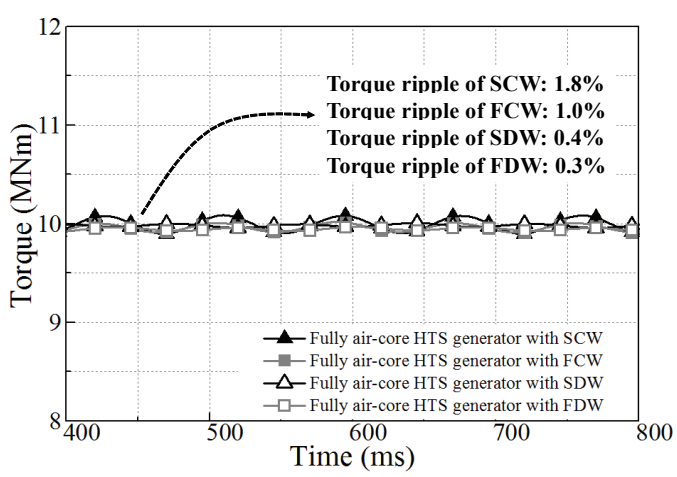

(a) Fully air-core types

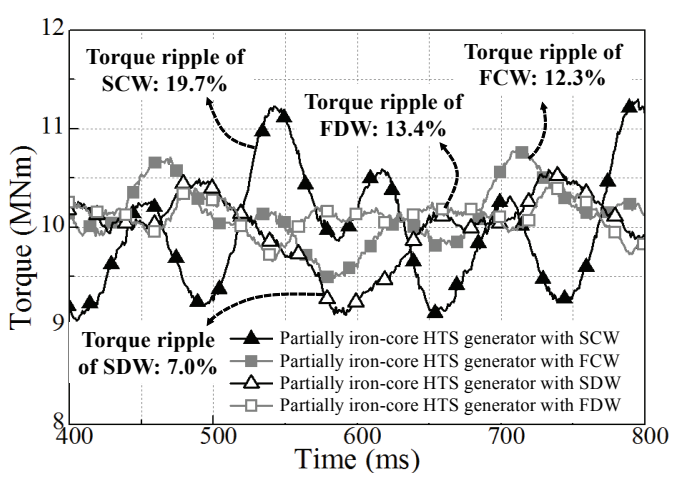

(b) Partially iron-core types

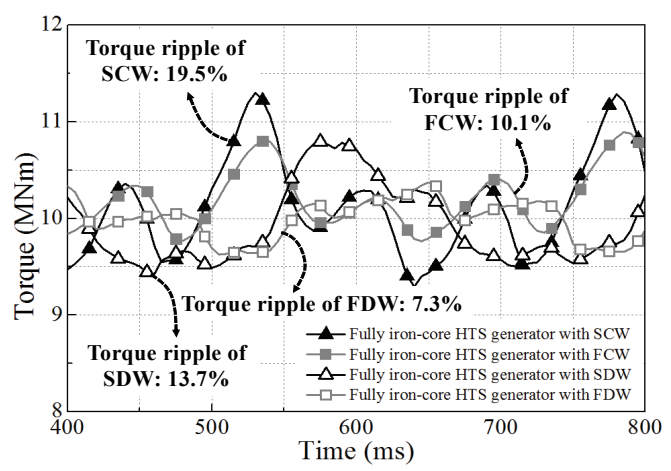

(c) Fully iron-core types

Fig. 4. Electromagnetic torque waveforms of the HTS generators

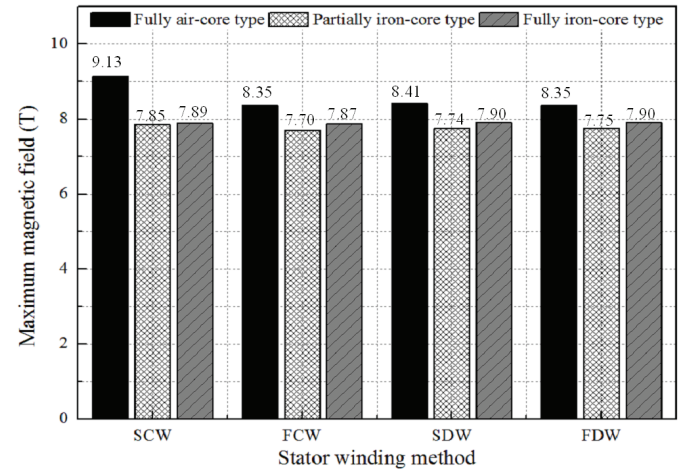

(a) Maximum magnetic field

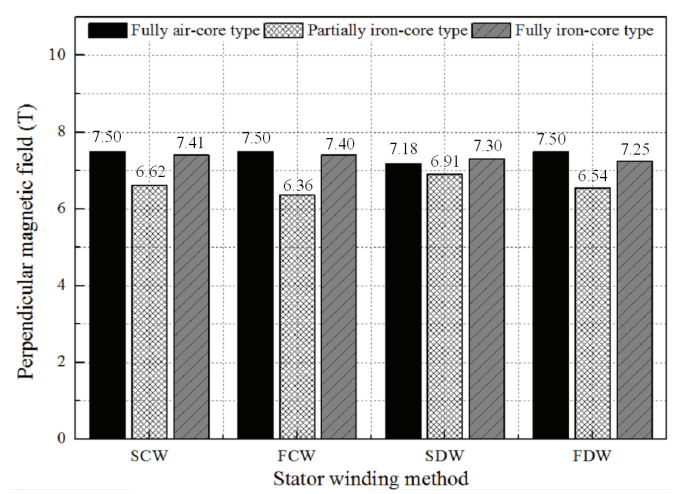

(b) Perpendicular magnetic field

Fig. 5. Magnetic field values of the HTS generators

type with FDW have the lowest values of torque ripples. An optimal design of stator slot shape will be required to reduce the torque ripple in the future.

The HTS wire is influenced by the perpendicular magnetic field because the shape of the HTS wire is the tape type. Therefore, the operating current is selected by the value of the perpendicular magnetic field. The values of the maximum magnetic field and perpendicular magnetic field of the HTS generators are illustrated in Fig. 5.

Table 4 represents the losses and efficiencies of the HTS generators. The stator coil losses of each stator winding type are equal due to the same total stator coil area. The efficiencies of fully air-core types are the highest at about $98.5 \%$, and the efficiencies of fully iron-core types are a little lower than the partially iron-core types due to the iron loss of rotor body.

\subsection{Comparative analysis of the HTS generators}

The HTS generators must be designed to use the least possible amount of HTS wire because the cost of the wire accounts for a substantial proportion of the manufacturing cost. However, in order to design the overall wind power system, the weight and volume of the HTS generators must also be considered. Fig. 6 shows the total length of the HTS wire and the volume and weight of generators. The volume and total length of the HTS wire in the fully ironcore type generators with $\mathrm{SCW}$ and $\mathrm{FCW}$ are the smallest 


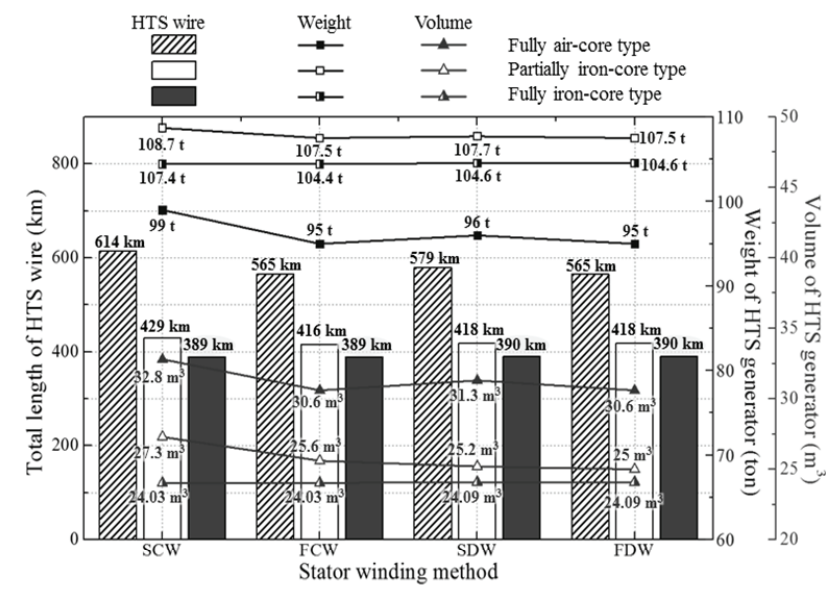

Fig. 6. Total length of the HTS wire, volume and weight of the 10 MW HTS generators

Table 5. Specifications of the $10 \mathrm{MW}$ fully iron-core type generator with FDW

\begin{tabular}{c|c}
\hline Specifications & Value \\
\hline Rated power (MW) & 10.5 \\
\hline Rated output voltage (kV) & 6.6 \\
\hline Rotating speed (rpm) & 10 \\
\hline Axial length (m) & 0.5 \\
\hline The number of poles & 24 \\
\hline Turns of DPC & 923 \\
\hline Total length of HTS wire (km) & 390 \\
\hline Operating current (A) & 104 \\
\hline Maximum magnetic field (T) & 7.90 \\
\hline Perpendicular magnetic field (T) & 7.25 \\
\hline Stator winding method & FDW \\
\hline The number of stator slots & 144 \\
\hline Turns of copper coil & 25 \\
\hline Air-gap length (mm) & 20 \\
\hline Diameter of SCSG (m) & 5.33 \\
\hline Volume of SCSG (m $\left.{ }^{3}\right)$ & 24.09 \\
\hline Active weight of SCSG (ton) & 104.6 \\
\hline
\end{tabular}

and shortest. The weight of the fully air-core type generators with FCW and FDW are the lightest because the mass density of the nonmagnetic material is lower than the magnetic material.

All items considered, the design of fully iron-core type generator with FDW is recommended for the $10 \mathrm{MW}$ class wind power system because weight and volume of three types of the generators are not significantly different, however, the total length of the HTS wire shows a huge difference over $200 \mathrm{~km}$ between the fully air-core types and fully iron-core types. Among the stator winding methods of fully iron-core types, FDW has the lowest torque ripple.

Table 5 shows the specifications of the $10 \mathrm{MW}$ fully iron-core type generator with FDW. The maximum magnetic flux density of the fully iron-core type generator with FDW is about $7.89 \mathrm{~T}$ at HTS field coil as depicted in Fig. 7, and the Fig. 8 shows the magnetic flux density of HTS rotor coil in fully iron-core type generator with FDW.

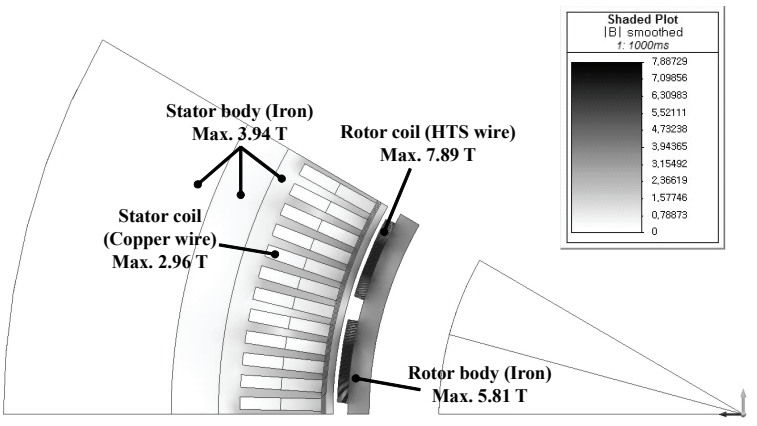

Fig. 7. Magnetic flux density of 1/24 model of the $10 \mathrm{MW}$ fully iron-core type generator with FDW
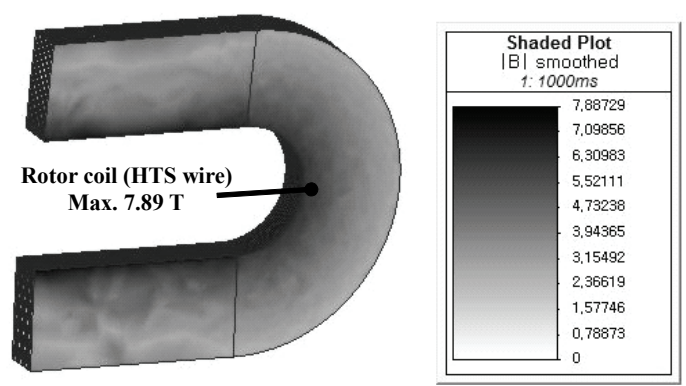

Fig. 8. Magnetic flux density of $1 / 2$ model of rotor coil in the 10MW fully iron-core type generator with FDW

\section{Conclusion}

This paper deals with designs of large scale air-core and iron-core HTS wind power generators to reduce their weight and volume and the total length of HTS wire. The three types of HTS generators such as fully air-core, partially iron-core, and fully iron-core are designed considering the various stator winding methods. As a result, the THD values of the HTS generators are less than 5\%, and the torque ripple of air-core type HTS generator with FDW is the lowest. In the case of the partially iron-core type with SDW and fully iron-core type with FDW, the torque ripples of these stator winding methods are lower than other stator winding methods. The efficiencies of the three types of HTS generators are $98 \%$ similar to each other. The volume and total length of the HTS wire in the fully iron-core type generators with SCW and FCW are the smallest and shortest. The fully air-core type generators with FCW and FDW are the lightest in weight. All items considered, the design of fully iron-core type HTS generator with FDW is recommended for the $10 \mathrm{MW}$ class wind power system. The results will be effectively utilized to design a large-scale HTS generator for wind power systems.

\section{Acknowledgements}

This research is financially supported by Changwon National University in 2013-2014. 


\section{References}

[1] International Wind Energy Development: Offshore Report 2013: Navigant's BTM Consult, 2012.

[2] Hae-Jin Sung, Gyeong-Hun Kim, Kwangmin Kim, Sung-Jun Jung, Minwon Park, In-Keun Yu, YoungGyun Kim, Haigun Lee and A-Rong Kim, "Practical Design of a $10 \mathrm{MW}$ Superconducting Wind Power Generator Considering Weight Issue," IEEE Trans. on applied supercond., vol. 23, no. 3, pp. 52018055201805, June 2012.

[3] Taiying Zheng, Seung-Tae Cha, Yeon-Hee Kim, Peter A. Crossley, Sang Ho Lee and Yong Cheol Kang, "Design and Evaluation of a Protection Relay for a Wind Generator Based on the Positive- and NegativeSequence Fault Components," Journal of Electrical Engineering \& Technology, vol. 8, no. 5, pp. 10291039, 2013.

[4] Hochang Jung, Cheol-Gyun Lee, Sung-Chin Hahn and Sang-Yong Jung, "Optimal Design of a DirectDriven PM Wind Generator Aimed at Maximum AEP using Coupled FEA and Parallel Computing GA," Journal of Electrical Engineering \& Technology, vol. 3, no. 4, pp.552-558, 2008.

[5] A. Hughes and T. J. E. Miller, "Analysis of fields and inductances in air-cored and iron-cored synchronous machines," Electrical Engineers, vol. 124, pp. 124: 121-126, Feb. 1977.

[6] T. J. E. Miller and A. Hughes, "Comparative design and performance analysis of air-cored and iron-cored synchronous machines," Electrical Engineers, vol. 124, pp. 127-132, Feb. 1977.

[7] Gunar Klaus, Markus Wilke, Joachim Frauenhofer, Wolfgang Nick and Heinz-Werner Neumüller, "Design Challenges and Benefits of HTS Synchronous Machines," Power Engineering Society General Meeting, pp. 1-8, June 2007.

[8] SuperPower Inc. [online]. Available: http://www.super power-inc.com.

[9] Keisuke Yoshizawa, So Noguchi and Hajime Igarashi, "Influence of Magnetic Property of Ferromagnetic Shield on High Field Magnet Analysis," IEEE Trans. on applied supercond., vol. 21, no. 3, pp. 2088-2091, June 2011.

[10] Proto Laminations Inc. [online]. Available: http:// pr otolam.com.

[11] 1547-2003-IEEE Standard for Interconnecting Distributed Resources with Electric Power Systems: IEEE SCC21, 2003, p. 13.

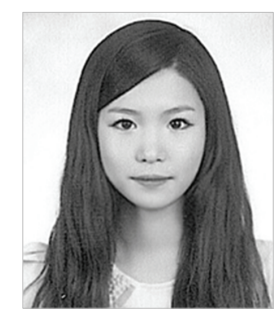

Hae-Jin Sung She received B.S. and M.S. degrees in electrical engineering from Changwon National University in 2012 and 2014. Her research interests are wind power system, superconducting generator.

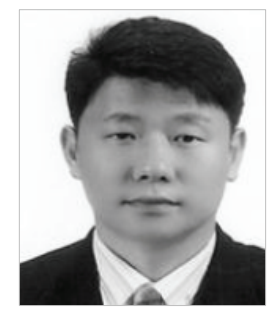

Minwon Park He received B.S degree in Electrical Engineering from Changwon National University in 1997 and his Master's and Ph.D. degrees in Electrical Engineering from Osaka University in 2000 and 2002, respectively. His research interests are the development of the simulation model of power conversion equipment and renewable energy sources using EMTP type Simulators.

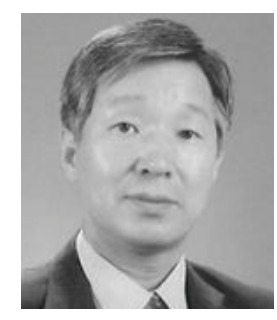

In-Keun Yu He received B.S degree in Electrical Engineering from Dongguk University in 1981 and his M.S. and $\mathrm{Ph} . \mathrm{D}$. degrees in Electrical Engineering from Hanyang University in 1983 and 1986, respectively. His research interests are electric energy storage and control systems, PSCAD/EMTDC and RTDS simulation studies, and renewable energy sources. 